\title{
Separation of R\&D Processes in a Biopharmaceutical R\&D
}

\author{
$\underline{\text { T. Miyashige }}^{\text {a }}$ and A. Fujii ${ }^{\text {b }}$ \\ ${ }^{a}$ Department of International Business, National Institute of Technology, Toyama College, Ebie-Neriya 1-2, \\ Imizu, Toyama, 933-0293 Japan \\ ${ }^{b}$ Faculty of Economics and Business Administration, The University of Kitakyushu, Kitagata 4-2-1, Kokura- \\ minamiku, Kitakyushu, Fukuoka, 802-8577 Japan \\ Email: miyasige@nc-toyama.ac.jp
}

\begin{abstract}
This paper describes the R\&D productivity of a biopharmaceutical company, with emphasis on separation of the research and development processes. Many previous studies focus pharmaceutical R\&D, but they focus low-molecular compound drug only. The pharmaceutical R\&D can be divided into the research and the development processes. The research process is the process to seek a NCEs (New Chemical Entities) or NBEs (New Biological Entities) candidate protected by patents. On the other hand, the development process makes one of the NCEs or NBEs into a new drug. For this reason, we analyze not only the research process but also the development process.
\end{abstract}

The estimation results for low-molecular compound drug R\&D are summarized as follows: (i) The research process shows decreasing returns to $R \& D$ investment scale, but the development process shows increasing returns; (ii) The empirical effect of patents on the number of new drug is not significant.

After the 2000s, most of the profit of the pharmaceutical companies is gained by biotech new drugs. We employ Amgen Inc. as an example of an independent biologic pharmaceutical company. We measured the research process output in terms of patents on underlying core technology, and the development process output in terms of patents concerning manufacturing or marketing final product. By regression analysis and case study method, we obtain three implications that contrast with previous results from chemical synthesis pharmaceutical companies: (i) Economies of scale may exist in both research and development processes; (ii) Persistency is more markedly seen in the development process than in the research process; (iii) Research and development processes tends to diverge.

Keywords: Biopharmaceutical $R \& D$, scale effect, separation of $R \& D$, Amgen Inc. 


\section{INTRODUCTION}

In this study, we analyze the R\&D productivity of a biopharmaceutical company, focusing on separation of the research and development processes.

The pharmaceutical industry in the recent two decades can be characterized in terms of two aspects: Blockbusters and biotech drugs. The pharmaceutical companies' profit have heavily relied on small number of new drugs with big sales, called blockbusters, and after 2000s, biotech drugs replace many of top-selling low-molecular compound drugs. This tendency calls for new productivity analysis of the industry.

Blockbusters is theoretically regarded as the internal resource contributes to its competitive advantage by the 'Value-Rareness-Inimitability-Organization (VRIO)' framework based on the 'Resource Based View (RBV)' theory (Barney, 1991; Wernerfelt, 1984). Barney (1991) suggested such internal resource should have economic value, rareness and inimitability jointly. Kranzler et al. (1995) and Boulton (2000) suggested the use of blockbuster as a measure of effective internal resource in pharmaceutical industry, because it enables business organizations to satisfy VRIO criteria. Their suggestion emphasizes proprietary firms' profit motivation, and reveals that previous studies have shortcomings in the selection of target variable.

\section{PREVIOUS STUDIES ON PHARMACEUTICAL R\&D}

Let us classify previous pharmaceutical R\&D studies on low-molecular compound drug into four groups, according to internal resource measurement.

The first group consists of the empirical studies by Gambardella (1992), Henderson and Cockburn (1996), and Schwartzman (1976), which measured internal resource by the number of pharmaceutical patents. The second group is those by Graves and Langowitz (1993), Jensen (1987), and Odagiri and Murakami (1992), which used the number of new chemical entities (NCEs). The third group is by Comanor (1965), Schwartzman (1976), and Vernon and Gusen (1974), which used a combination of the number of NCEs and the sales amount. The common feature of the studies in the three groups is that they did not analyze the final output of the whole R\&D process as described in Section 3 below.

The fourth group is formed by Cockburn and Henderson (2001), which used the number of approved new drugs. This study was the first attempt to analyze development process (new drugs are outcome indices of whole R\&D processes). The explained variable has inimitability and economic value, but it lacks rareness.

Miyashige and Fujii (2014) used blockbuster as an output measure of pharmaceutical R\&D to overcome these shortcomings. If they take blockbuster as final output measure, the NCE candidate protected by the patent is treated simply as intermediate inputs to the whole R\&D process. Their study analyzed the research and the development processes jointly, concluding: (i) The research process shows decreasing returns to R\&D investment scale, while the development process shows increasing returns; (ii) The empirical effect of patents on the number of new drug is not significant.

After 2000s, biotech new drugs come to prevail as the biggest products, and the fact that previous studies focus low-molecular compound drug only becomes some kind of drawbacks. Binder (2008) first analyzed biopharmaceutical R\&D of Amgen Inc., and Hughes (2011) analyzed that of Genentech Inc. But these studies applied case study methodology on these firms, and so, to the best of our knowledge, there is no quantitative analysis on biopharmaceutical R\&D in this field.

\section{RESEARCH AND DEVELOPMENT PROCESSES}

The pharmaceutical R\&D can be divided into the research and the development processes.

In the low-molecular compound drug R\&D, the research process is the process to determine a NCE candidate for development. A NCE candidate protected by the patent results from the research process. Each research project is carried out by a small unit of individual researchers, and these units seek different NCEs independently. The success of each individual research project depends highly on serendipity, rather than large R\&D investment.

The development process makes up one of the NCEs into an approved new drug. This process goes from the preclinical trial to the clinical trial. In the development process, especially at the clinical trial, a vast amount 
of R\&D investment and many large organized activities are required. Small number of approved new drugs with big sales, called blockbusters, contributes to the profit of pharmaceutical companies as described above. In the low-molecular compound drug development process, new technologies to make up a NCEs into an approved new drug are not required.

On the other hand, in a biopharmaceutical R\&D, the research process is the process to seek a NBEs (New Biological Entities) candidate protected by the patent. The characteristics of biotech new drug research are similar to the low-molecular compound drug research. The development process makes up one of the NBEs into an approved new drug. In the biotech drug development process, new technologies to make up a NBEs into an approved new drug are required. In biopharmaceutical R\&D, both research process and development process require a new technologies. So we measured the research process output in terms of patents on underlying core technology, and the development process output in terms of patents concerning manufacturing or marketing final product.

\section{MODEL AND DATA}

We set up a simultaneous equations model to estimate the relation between R\&D investment and each of two different R\&D processes. We follow Fujii and Miyashige (2009) formulation as:

(1) $M_{t}=\alpha_{0}+\alpha_{1} M_{t-1}+\alpha_{2} R_{t}+U_{t}$

(2) $A_{t}=\beta_{0}+\beta_{1} A_{t-1}+\beta_{2} M_{t-1}+\beta_{3} R_{t}+V_{t}$,

where $A_{t}$ is the number of patents newly acquired by the company at time period $t$, concerning manufacturing or marketing its final product; $M_{t}$ is the number of newly acquired patents on underlying core technology; $R_{t}$ is the annual total of R\&D investment made by the company. $U_{t}$ and $V_{t}$ are disturbances. Equations (1) and (2), respectively, attempts to depict the numerical relations between the variables in research and development processes.

Data are taken from Patent Report: Antibiotics (2014) issued by Japan Patent Office. We use data on the United Stated rate of inflation from IMF World Economic Outlook Databases (April, 2015) to convert the R\&D investment to the corresponding value of year 2012. The descriptive statistics are summarized in Table 1.

Table 1. Descriptive Statistics (year 1991-2005)

$\begin{array}{llll}\text { Variable } & \text { Mean } & \text { Std, Dev. } & \text { Min. }\end{array}$

\begin{tabular}{rrrrr}
\hline \hline$M_{t}$ & 22.200 & 23.140 & 0 & 75 \\
\hline$A_{t}$ & 28.267 & 30.307 & 0 & 85 \\
\hline$R_{t}$ & 1123.533 & 769.300 & 208 & 2755 \\
\hline
\end{tabular}

\section{EMPIRICAL ANALYSIS}

Table 2 reports result of OLS regression applied to equations (1) and (2).

First, we analyze economy of scale by computing the scale elasticity. At the sample mean $(\partial M / \partial R) /(M / R)$ is estimated to be 1.569 , while $(\partial A / \partial R) /(A / R)=1.232$. This implies economy of scale exists in both subprocesses, and this result contrasts to that of previous low-molecular compound drug R\&D analysis.

Second, parameters $\left(\alpha_{1}, \beta_{1}\right)$ are expected to stay between 0 and 1 , and they measure the persistency of the dependent variables. The estimation result claims persistency presents in equation (2) (development 
process), but not that clear in research process. This resembles results of Fujii and Miyashige (2009), which analyzed seven large pharmaceutical companies for low-molecular drugs and reports the persistency is larger in magnitude in development process than in research process.

Third, we can evaluate the connection between the sub-processes by $\beta_{2}$. The statistically significant negative sign of the estimate implies there may be some latent pressure into separating the subprocesses.

Table 2. OLS Estimation Result (year 1991-2005)

\begin{tabular}{|c|c|c|c|c|c|}
\hline \multicolumn{3}{|c|}{ Equation (1) } & \multicolumn{3}{|c|}{ Equation (2) } \\
\hline Parameter & Estimate & & Parameter & Estimate & Std, Err. \\
\hline$\alpha_{0}$ & -6.096 & 6.523 & $\beta_{0}$ & -4.566 & 7.461 \\
\hline$\alpha_{1}$ & -0.331 & 0.261 & $\beta_{1}$ & $0.537 * *$ & 0.244 \\
\hline \multirow[t]{2}{*}{$\alpha_{2}$} & $0.031 * * *$ & 0.007 & $\beta_{2}$ & $-0.679 * *$ & 0.290 \\
\hline & & & $\beta_{3}$ & $0.031^{* *}$ & 0.010 \\
\hline Adj. R2 & 0.643 & & Adj. R2 & 0.74 & \\
\hline $\begin{array}{l}\text { Number of } \\
\text { Observations }\end{array}$ & 15 & & $\begin{array}{l}\text { Number of } \\
\text { Observations }\end{array}$ & 15 & \\
\hline
\end{tabular}

$* *, * * *$ : Statistically significant at 5\%,1\%, respectively.

\section{DISCUSSION AND CONCLUSIONS}

Using regression analysis, we obtain three implications that contrast with previous results from chemical synthesis pharmaceutical companies: (i) Economies of scale may exist in both research and development processes; (ii) Persistency is more markedly seen in the development process than in the research process; (iii) Research and development processes tends to diverge.

After Amgen Inc. was established by three researches in 1980, they began to research EPOGEN (epoetin alfa) and NEUPOGEN (filgrastim). Those patents on underlying core technology were researched by Amgen, and they started to makes up those NBEs into an approved new drug. The patents concerning manufacturing or marketing final product were discovered by Amgen. After FDA (The US Food and Drug Administration) approved EPOGEN in 1989 and NEUPOGEN in 1991 as new drugs, EPOGEN and NEUPOGEN grew up to blockbusters.

Amgen researched patents on underlying core technology related Aranesp (darbepoetin alfa) and Neulasta (Pegfilgrastim) in 1990s, and they started to makes up those NBEs into an approved new drugs. The patents concerning manufacturing or marketing final product were made a discovery by Amgen. Those drugs grew up to blockbusters after approved by FDA. 
Amgen created biotech blockbusters by own research and development capability until 1990s. But they began to buy research biotech outcome (NBEs) from small ventures after 1990s. Amgen acquired Synergen Inc. to get NBE of Kineret (Anakinra) in 1994, and acquired Abgenix Inc. to get NBE of Vectibix (panitumumab) in 2006. But Amgen discovered patents concerning manufacturing or marketing final product for those NBEs. Kineret and Vectibix grew up to blockbusters.

Amgen acquired Micromet Inc. to get NBE of BLINCYTO (blinatumomab) in 2012, and acquired Onyx Inc. to get NBE of Kyprolis (Carfilzomib) in 2013. But Amgen discovered patents concerning manufacturing or marketing final product for those NBEs. A few years later, BLINCYTO and Kyprolis will grow up to blockbusters. Our regression analysis results are consistent with those established facts.

\section{REFERENCES}

Barney, J. B. (1991). Firm resources and sustained competitive advantage. Journal of Management 17, 99120.

Binder, G. and Bashe, P. (2008). Science Lessons: What the Business of Biotech Taught Me About Management. Boston: Harvard Business School Press.

Boulton, W. R. (2000). Consolidations and alliances: challenges to US pharmaceutical leadership. Journal of Health Care and Society 10(1), 73-111.

Cockburn, I. M. and R. M. Henderson (2001). Scale and scope in drug development: Unpacking the advantages of size in pharmaceutical research. Journal of Health Economics 20, 1033-1057.

Comanor, W. S. (1965). Research and technical change in the pharmaceutical industry. Review of Economics and Statistics 47, 182-190.

Fujii, A. and T. Miyashige (2009). Scale economies of pharmaceutical patent and blockbuster R\&D with possible endogeneity and dynamics. In R. S. Anderssen, R. Braddock, and L. Newham (Eds.), 18th World IMACS Congress and MODSIM09 International Congress on Modelling and Simulation, pp. 1113-1118. Modelling and Simulation Society of Australia and New Zealand and International Association for Mathematics and Computers in Simulation.

Gambardella, A. (1992). Competitive advantages from in-house scientific research: The US pharmaceutical industry in the 1980s. Research Policy 2, 391-407.

Graves, S. B. and N. S. Langowitz (1993). Innovative productivity and returns to scale in the pharmaceutical industry. Strategic Management Journal 14, 593-605.

Henderson, R. and I. Cockburn (1996). Scale, scope and spillovers: the determinants of research productivity in drug discovery. RAND Journal of Economics 27, 32-59.

Hughes, S. S. (2011). Genentech: The Beginnings of Biotech. Chicago: University of Chicago Press.

Jensen, E. J. (1987). Research expenditures and the discovery of new drugs. Journal of Industrial Economics $36,83-95$.

Kranzler, J., D. Taylor and F. Weber (1995). Going for the gold: rules for a new game in drug development. The McKinsey Quarterly 5, 70-88.

Miyashige, T., A. Fujii, and K. Kimura (2007). Are research and development processes independent in the pharmaceutical R\&D? In L. Oxley and D. Kulasiri (Eds.), MODSIM 2007 International Congress on Modelling and Simulation, pp. 74-80. Modelling and Simulation Society of Australia and New Zealand.

Miyashige, T., and Fujii, A. (2014). Iyakuhin kigyou no kenkyu kaihatsu senryaku: Bunri suru kenkyu kaihatsu to baio gijyutsu no taitou [Strategic R\&D of Pharmaceutical Companies: Emerging Biotechnology and Diverging R\&D Processes]. Tokyo: Keibun-sha (in Japanese).

Odagiri, H. and N. Murakami (1992). Private and quasi-social rates of return on pharmaceutical R\&D in Japan. Research Policy 21, 335-345. 
Miyashige and Fujii, Separation of R\&D Processes in a Biopharmaceutical R\&D

Schwartzman, D. (1976). Innovation in the Pharmaceutical Industry. Baltimore: Johns Hopkins University Press.

Vernon, J. M. and P. Gusen (1974). Technical change and firm size: the pharmaceutical industry. Review of Economics and Statistics 56, 294-302.

Wernerfelt, B. (1984). A resource-based view of the firms. Strategic Management Journal 5, 171-180. 